\title{
Seit Jahren bin ich jeden Tag pünktlich.
} Warum dürfen meine Zahlungseingänge nicht auch mal pünktlich sein?

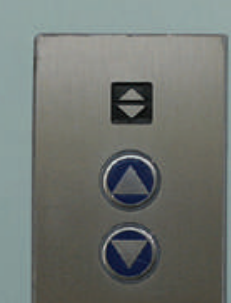

\section{FMH INKASSO}

Encath AG - Koordinationsstelle Postfach 624, 2501 Biel Tel. 0323443969 - Fax 0323443966 mail@fmhinkasso.ch - www.fmhinkasso.ch Inkassodienstleistungen für Ärzte

\section{FMH FACTORING}

Encath AG - Koordinationsstelle Neuengasse 5, 2502 Biel Tel. 0325603910 - Fax 0325603911 mail@fmhfactoring.ch - www.fmhfactoring.ch Honorarabrechnung für Ärzte inklusive Zahlungsgarantie und Übernahme des Verlustrisikos

\section{INKASSODIENSTLEISTUNGEN \& HONORARABRECHNUNG FÜR ÄRZTE}

$\square \quad$ Bitte senden Sie mir unverbindlich und kostenlos Unterlagen über das komplette Leistungspaket von:

$\square \quad \mathrm{FMH}$ Inkasso Services

$\square \quad$ FMH Factoring Services

$\square \quad$ Ich wünsche eine persönliche Beratung. Bitte rufen Sie an: Telefon

Beste Anrufzeit

Name der Praxis

Ansprechpartner

Adresse/Stempel 